\title{
PENGEMBANGAN SET PRAKTIKUM PEMBIASAN CAHAYA UNTUK PEMBELAJARAN FISIKA DI SMA
}

\author{
Arum Sri Rahayu*), Vina Serevina, Raihanati \\ Program Studi Pendidikan Fisika, Fakultas Matematika dan Ilmu Pengetahuan Alam, Universitas Negeri Jakarta, \\ Jalan Rawamangun Muka No.1 Jakarta Timur, 13220. \\ *)Email: arumsrirahayu@gmail.com
}

\begin{abstract}
Abstrak
Penelitian ini bertujuan untuk mengembangkan set praktikum fisika untuk SMA kelas X pada sub materi pembiasan cahaya. Metode penelitian yang digunakan yaitu metode penelitian pengembangan R\&D (Research and Development) model Borg dan Gall, dengan empat tahap pengembangan, yaitu: 1. studi pendahuluan, 2. pengembangan produk, 3. validasi dan revisi produk, 4. uji coba produk. Penelitian dilakukan pada bulan januari-mei 2016 di Laboratorium Fisika FMIPA, Universitas Negeri Jakarta. Set praktikum pembiasan cahaya ini telah melalui uji validasi yang melibatkan ahli materi dan ahli media pembelajaran dengan persentase pencapaian $95.01 \%$ menurut ahli materi, $94.14 \%$ menurut ahli media pembelajaran. Uji coba set praktikum ini dilakukan kepada 63 peserta didik SMA dan empat guru fisika di SMAN 58 Jakarta dengan persentase capaian sebesar $88.45 \%$ menurut guru fisika dan $80.58 \%$ menurut peserta didik SMA. Hasil ujicoba set praktikum mampu menunjukkan berkas sinar yang berbelok ketika melewati dua medium yang berbeda, dan mampu menunjukkan besar simpangan sinar yang berbelok yang dapat digunakan untuk menentukan indeks bias medium yang dilalui sinar tersebut dengan menggunakan persamaan Snellius. Dengan demikian dapat disimpulkan pengembangan set praktikum pembiasan cahaya layak digunakan sebagai media pendukung pembelajaran fisika di SMA.
\end{abstract}

Kata-kata kunci: Set Praktikum, Pembiasan Cahaya, Indeks Bias

\begin{abstract}
This research aims to develop a set of practical work for $11^{\text {th }}$ grade Senior High School at sub light refraction material. The method of the research is $R \& D$ (Research and Development) of Borg and Gall which is limited to four developmental stages: 1. Preliminary study, 2. Product development, 3. Validation and Product Revision, 4. Products trials. This research was conducted from January to May 2016 in FMIPA's Physics Laboratory of State University of Jakarta. Set refraction of light has been through validity test involving matter experts that consist of physics lecturer and physics education lecturer with the percentage $95.01 \%$ according to matter experts, $94.14 \%$ according to media expert. The field test of this set conducted to 63 Senior High School students and three physics teachers at SMAN 58 Jakarta with the percentage of achievement $88.45 \%$ according to physics teacher and $80.58 \%$ according to Senior High School students. The results of the study showed the bent ray that pass through two different mediums and the angle deviation of light that used for determining the index refractions which passed by light using the Snellius's equation. Based on this research, it can be summarized that the development of set refraction is useful for material physics at senior high school.
\end{abstract}

Keywords: Set of Refraction ,Refractions, Index Refractions

\section{Pendahuluan}

Fisika merupakan ilmu pengetahuan yang berdasarkan pada percobaan. Suatu pengetahuan yang tumbuh dari pengalaman-pengalaman, sedangkan pengalaman itu didapatkan dengan jalan melakukan percobaan. [1]
Pada pembelajaran fisika pemahaman konsep dengan pengalaman belajar langsung dapat dilakukan melalui kegiatan praktikum. Praktikum merupakan kegiatan yang dilakukan untuk memecahkan atau membuktikan suatu teori, yang meliputi, mengamati, mengukur, sehingga dipeoleh data yang kemudian dipergunakan untuk menarik kesimpulan [2]. 
Pengetahuan teoritis fisika disertai dengan kerja praktek dapat memastikan efektivitas belajar mengajar fisika, selain itu tahapan-tahapan praktikum dapat mengembangkan kerja ilmiah siswa yang pada gilirannya mendukung penguasaan siswa pada konsep yang diajarkan serta siswa mampu menerapkan pemahamannya dalam situasi yang berbeda [3].

Alat dan bahan praktikum merupakan salah satu komponen yang harus dipersiapkan sebelum melakukan kegiatan praktikum [4]. Alat praktikum yang baik adalah alat praktikum yang dapat menunjukkan prinsip, gejala atau hukum alam, dan mengandung atau membawakan konsep-konsep yang dipelajari [5]. Salah satu hukum fisika yang diajarkan di Sekolah Menengah Atas adalah pembiasan cahaya. fenomena langsung dari pembiasan cahaya atau pembelokan cahaya ketika melewati dua medium yang berbeda indeks biasnya, dengan menggunakan sinar laser dan pengatur sudut sinar datang akan membuat pengguna alat lebih tertarik untuk menggunakannya [6].

Berdasarkan hasil analisis kebutuhan yang telah dilakukan menunjukkan bahwa $85,71 \%$ siswa mengalami kesulitan dalam belajar fisika dengan alasan terlalu banyak simbol, rumus, dan istilah yang digunakan, 91,07\% siswa belum perrnah melihat set praktikum pembiasan cahaya, kemudian didapat juga data bahwa $93,75 \%$ siswa mendukung, dan tertarik dengan adanya pengembangan pendukung pembelajaran fisika berupa set praktikum pembiasan cahaya.

Alat praktikum pembiasan cahaya umumnya digunakan kaca plan paralel. Alat ini digunakan untuk memperlihatkan pembiasan dan menghitung indeks bias udara dan kaca plan paralel, tetapi sudut kritis dan pemantulan sempurna sulit diperlihatkan. Sehingga alat praktikum fisika khususnya untuk konsep pembiasan cahaya, indeks bias, sudut kritis dan pemantulan tidak dilibatkan dalam proses pembelajaran fisika.

Berdasarkan uraian diatas, diperlukan suatu set praktikum yang dapat menunjukkan peristiwa pembiasan cahaya, sudut kritis dan pemantulan sempurna pada beberapa medium yang berbeda. Maka dikembangkan penelitian dengan judul "Pengembangan Set Praktikum Pembiasan Cahaya untuk Pembelajaran Fisika di SMA".

\section{Metode Penelitian}

Metode yang digunakan dalam penelitian ini yaitu metode penelitian dan pengembangan (Development Research). Model Borg and Gall, Penelitian pengembangan pendidikan ialah suatu proses yang digunakan untuk mengembangkan dan memvalidasi produk yang telah ada yang dapat di pertanggung jawabkan [7].

Langkah-langkah pengembangan model Borg and Gall dapat dilakukan secara lebih sederhana dengan melibatkan empat langkah utama tanpa mengurangi esensialnya, yaitu: 1. studi pendahuluan,
2. pengembangan produk, 3. validasi dan revisi produk, 4. uji coba produk.

Produk yang dikembangkan yaitu set praktikum pembiasan cahaya dengan bagian utama komponen alat berupa sinar laser (sumber sinar) dan lengan pengatur sudut sinar datang. Berkas sinar datang dan sinar bias dapat dilihat besar sudutnya dengan mengacu pada skala busur yang menyatu pada dinding dalam wadah tabung medium zat cair dan papan skala busur pada zat padat yang dibuat depan belakang.

Berikut ini adalah gambar desain awal set praktikum pembiasan cahaya.

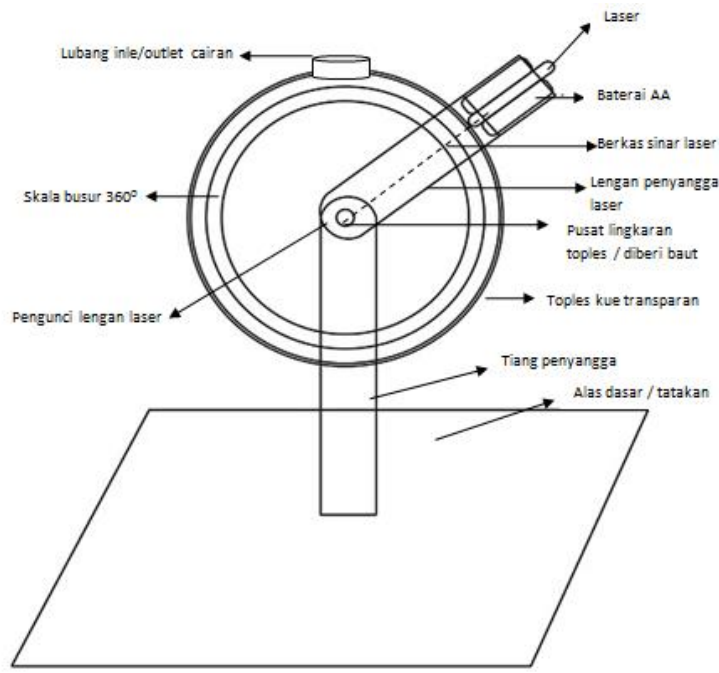

Gambar 1. Desain awal set praktikum

\section{Hasil dan Pembahasan}

Desain pengembangan set praktikum pembiasan cahaya dibuat dengan mempertimbangkan tujuan penggunaan, kepraktisan dalam penggunaan serta pemanfaatan set praktikum dalam proses pembelajaran [8].

Komponen-komponen yang terdapat di dalam set praktikum pembiasan cahaya dengan sinar laser dan pengatur sudut sinar datang antara lain:

\section{a. Tabung dan Papan Berskala yang dibuat depan belakang}

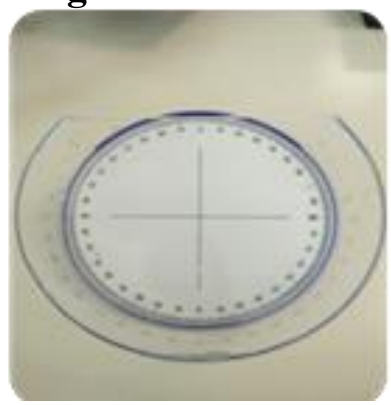

Gambar 2. Tabung dengan skala busur 


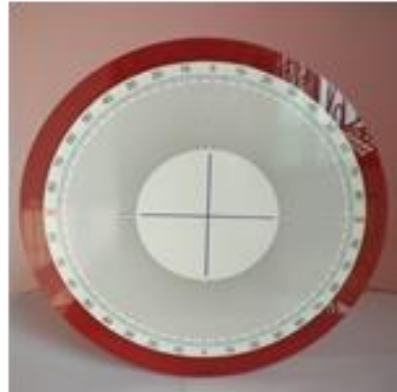

Gambar 3. Papan berskala

\section{b. Dudukan Tabung dan Lengan Pemutar}

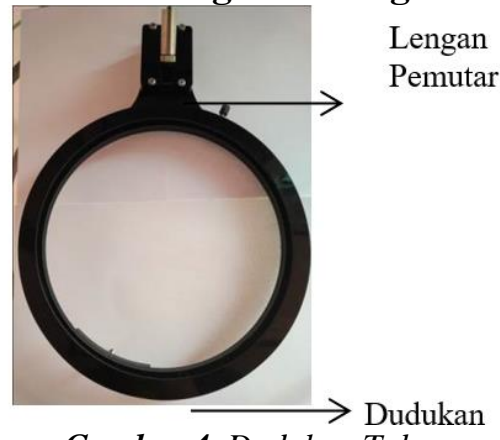

Gambar 4. Dudukan Tabung

\section{c. Set Praktikum Pembiasan Cahaya Pada} Zat Cair

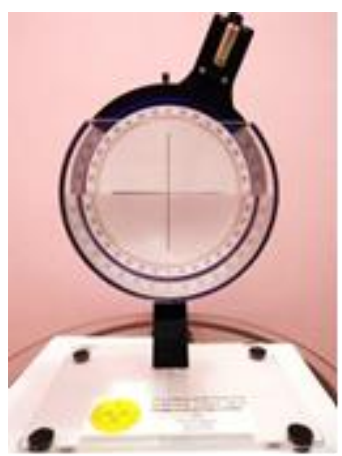

Gambar 5. Set praktikum pembiasan cahaya pada zat cair

\section{d. Set Praktikum Pembiasan Cahaya Pada Zat Padat}

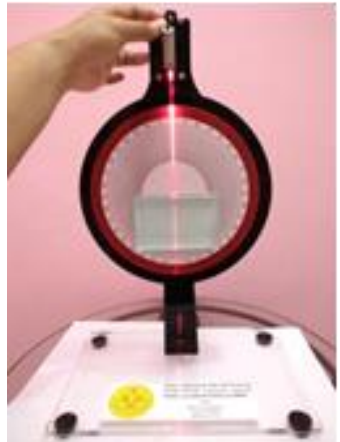

Gambar 6. Set praktikum pembiasan cahaya pada zat padat

\subsection{Hasil uji validasi tenaga ahli (dosen)}

Data hasil uji validasi dan ujicoba didekripsikan untuk menganalisis tingkat kualitas set praktikum pembiasan cahaya yang telah dikembangkan. Responden uji validasi terdiri dari 2 dosen ahli media 1 laboran dan 2 dosen ahli materi. Selama proses validasi, dilakukan revisi terhadap bagian fungsi alat sesuai dengan saran dan kritik dari validator. Proses revisi dilakukan karena masih ada kekurangan atau kesalahan yang perlu diperbaiki pada setiap bagian fungsi set praktikum yang dikembangkan guna mendapatkan kualitas produk dengan kategori sangat baik. Berikut ini adalah diagram hasil uji validasi set praktikum pembiasan cahaya:

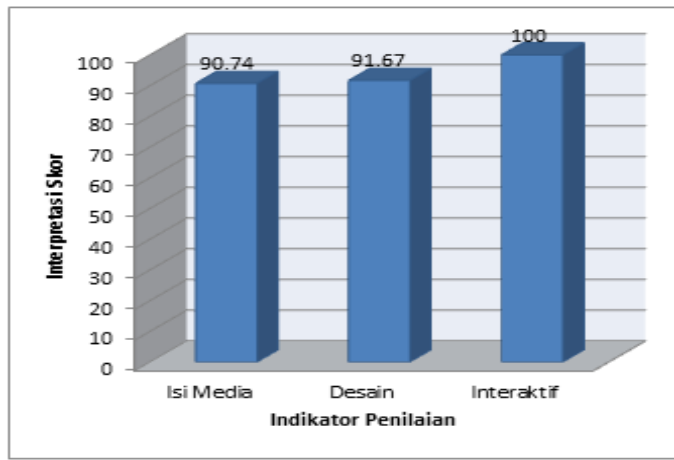

Gambar 7. Diagram hasil uji validasi oleh ahli media

Berdasarkan ketiga aspek penilaian oleh dosen ahli media yaitu isi media mendapat interpretasi skor $90,74 \%$, desain sebesar 91,67\%, dan interaktif sebesar $100 \%$. Rentang interpretasi skor rata-rata berada pada $80-100 \%$ (sangat baik).

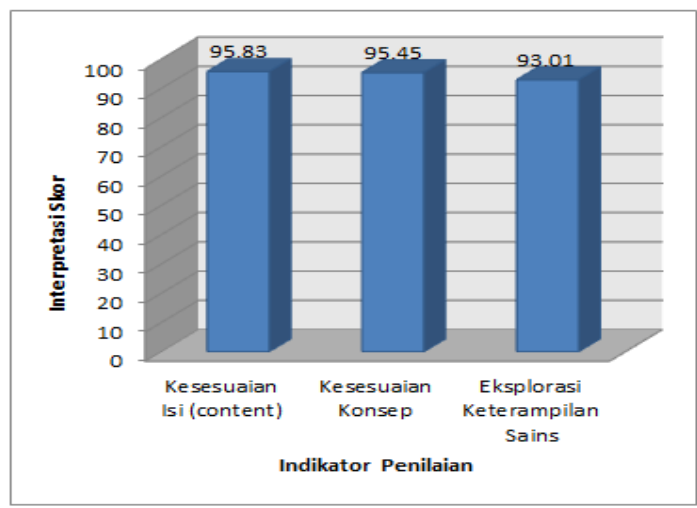

Gambar 8. Diagram hasil uji validasi oleh ahli materi

Berdasarkan ketiga aspek penilaian oleh dosen ahli materi yaitu kesesuaian isi (content) mendapat interpretasi skor 95,83\%, kesesuaian konsep sebesar $95,45 \%$, dan eksplorasi keterampilan proses sains sebesar $93,75 \%$. Rentang interpretasi skor rata-rata berada pada 80-100\% (sangat baik). 
Setelah dilakukan uji validasi oleh tenaga ahli (dosen) diperoleh masukan-masukan diantaranya:

a. memvariasikan zat cair dan zat padat lebih dari satu

b. Memvariasikan sumber cahaya yang digunakan

c. Membuat box penyimpanan yang sesuai

d. Meminimalisir kesalahan paralaks dalam membaca sudut bias utuk zat cair

\subsection{Uji validasi terhadap guru}

Berdasarkan kelima aspek penilaian yaitu kesesuaian isi (content) mendapatkan interpretasi skor $93,75 \%$, kesesuaian konsep sebesar 90,18\%, media sebesar $87,5 \%$, desain sebesar $87,5 \%$ dan interaktif $83,33 \%$. Rentang interpretasi skor rata-rata berada pada rentang $80-100 \%$ (sangat baik).

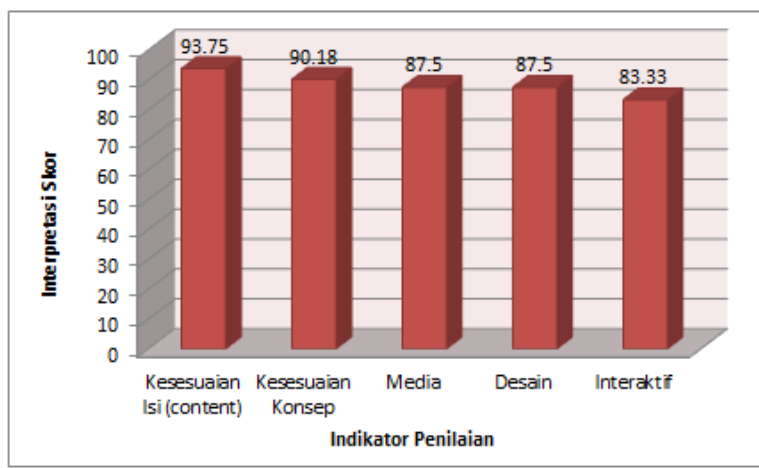

Gambar 9. Diagram validasi guru

Secara keseluruhan, validasi set praktikum pembiasan cahaya oleh tenaga ahli (guru) mendapat berbagai saran dan masukan untuk menambah nilai guna dari set praktikum yaitu: Set praktikum pembiasan sudah cukup bagus namun supaya lebih jelas terlihat cahaya pembiasannya lebih baik menggunakan warna hijau.

\subsection{Uji coba set praktikum terhadap siswa}

Berdasarkan hasil ujicoba terhadap siswa, Didapatkan interpretasi skor untuk kedua aspek penilaian berada pada rentang $80-100 \%$ (sangat baik). Dari hasil kuesioner, siswa menyatakan lebih mudah dalam memahami konsep pembiasan cahaya, sudut kritis dan pemantulan sempurna melalui percobaan secara langsung.

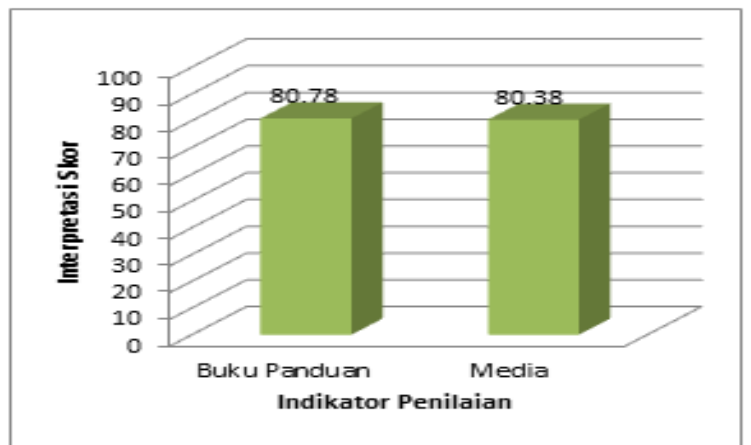

Gambar 10. Diagram hasil uji coba siswa

\subsection{Data hasil uji set praktikum}

Tabel 1 Hasil perhitungan indeks bias air dengan sudut datang dari udara ke air

\begin{tabular}{|c|c|c|c|}
\hline No. & Sudut datang $\left(\boldsymbol{\theta}_{\mathbf{1}}\right)$ & Sudut bias $\left.\boldsymbol{\theta}_{\mathbf{2}}\right)$ & $\mathbf{n}_{\mathbf{2}}$ \\
\hline $\mathbf{1}$ & $20^{\circ}$ & 15 & 1,32 \\
\hline $\mathbf{2}$ & $30^{\circ}$ & 23 & 1,30 \\
\hline $\mathbf{3}$ & $40^{\circ}$ & 30 & 1,30 \\
\hline $\mathbf{4}$ & $45^{\circ}$ & 33 & 1,30 \\
\hline $\mathbf{5}$ & $50^{\circ}$ & 36 & 1,30 \\
\hline \multicolumn{2}{|c|}{ Rata-Rata Indeks Bias } & 1,304 \\
\hline
\end{tabular}

Tabel 2 Hasil perhitungan indeks bias air dengan sudut datang dari udara ke kaca

\begin{tabular}{|c|c|c|c|}
\hline No. & Sudut datang $\left(\boldsymbol{\theta}_{\mathbf{1}}\right)$ & Sudut bias $\left(\boldsymbol{\theta}_{\mathbf{2}}\right)$ & $\mathbf{n}_{\mathbf{2}}$ \\
\hline $\mathbf{1}$ & $20^{\circ}$ & 13 & 1,52 \\
\hline $\mathbf{2}$ & $30^{\circ}$ & 19 & 1,54 \\
\hline $\mathbf{3}$ & $40^{\circ}$ & 25 & 1,52 \\
\hline $\mathbf{4}$ & $45^{\circ}$ & 28 & 1,51 \\
\hline $\mathbf{5}$ & $50^{\circ}$ & 30 & 1,53 \\
\hline \multicolumn{3}{|c|}{ Rata-Rata Indeks Bias } & 1,524 \\
\hline
\end{tabular}

Presentase error perbandingan indeks bias hasil perhitungan dan secara teoritik alat praktikum pembiasan cahaya pada air sebesar $2 \%$, Sedangkan presentase error perbandingan indeks bias hasil perhitungan dan secara teoritik alat praktikum pembiasan cahaya pada kaca plan pararel sebesar $4,4 \%$.

\section{Kesimpulan}

Pada penelitian ini telah berhasil dikembangkan set praktikum untuk sub materi pembiasan cahaya dengan sinar laser dan pengatur sudut sinar datang dan hasil yang didapat dari hasil validasi dosen dan guru set praktikum ini dapat disimpulkan layak menjadi set praktikum dalam proses pembelajaran fisika di sekolah.

\section{Ucapan Terima Kasih}

Penulis mengucapkan terima kasih kepada program studi Pendidikan Fisika, Universitas Negeri Jakarta, SMA Negeri 58 Jakarta, dan semua pihak yang telah membantu terselesainya penelitian ini.

\section{Daftar Acuan}

[1] Erniawati, d. Penggunaan media praktikum berbasis video dalam pembelajaran IPA-fisika untuk meningkatkan hasil belajar siswa pada materi pokok suhu dan perubahannya. Jurnal Sains dan Pendidikan Fisika (2014), 269-273.

[2] Amien, M. Buku Pedoman Laboratorium dan Petunjuk Praktikum Pendidikan IPA Umum (General Science) Untuk Lembaga Pendidikan 
Tenaga Kependidikan. Jakarta: Departemen Pendidikan dan Kebudayaan (1988).

[3] Hasbi, M. A. Pengembangan Alat Peraga Listrik Dinamis (APLD) Berbasis Inkuiri untuk Meningkatkan Penguasaan Konsep Siswa. Jurnal Penelitian Pendidikan IPA JPPIPA (2015).

[4] Wibowo, W. S. Persiapan Alat dan Bahan Praktikum IPA. 3 (2015).

[5] Prasetyarini, A. Pemanfaatan Alat Peraga IPA untuk Meningkatkan Pemahaman Konsep Fisika pada Siswa SMP Negeri 1 Bulu pesantren Kebumen Tahun Ajaran 2012/2013. Radiasi, 1 (2012).

[6] Tipler, A. Physics for Scientists and Engineers Diterjemahkan oleh Bambang Soegijono. Fisika untuk Sains dan Teknik. Edisi. 3 Cet. 1. Jilid II. Jakarta: Erlangga (2001).

[7] Borg W.R. and Gall M.D. Educational Research An Introduction, 4th edition. London: Longman Inc (1989).

[8] Departemen Pendidikan. Pedoman Pembuatan Alat Peraga Fisika untuk SMA. Jakarta: Kemendikbud.pdf (2011). 
